\title{
STUDY OF PROGNOSIS OF ATRIOVENTRICULAR BLOCKS VERSUS INTRAVENTRICULAR BLOCKS IN ACUTE MYOCARDIAL INFARCTION
}

\author{
Nelaballi Srichandhan Reddy¹, Bachu Narayanaswamy Raghavendra Prasad², Kamarti Prabhakar3, Kondaveeti Reddy Prasad ${ }^{4}$ \\ ${ }_{1}^{1}$ Post Graduate, Department of General Medicine, Sri Devaraj Urs Medical College. \\ 2Professor, Department of General Medicine, Sri Devaraj Urs Medical College. \\ 3 Professor and HOD, Department of General Medicine, Sri Devaraj Urs Medical College. \\ ${ }^{4}$ Assistant Professor, Department of General Medicine, Sri Devaraj Urs Medical College.
}

\begin{abstract}
Myocardial infarction is a Global epidemic, and it is as large as the new epidemic afflicting population worldwide. According to the National Commission on Macro-economics and Health, there would be around 62 million patients with Coronary Artery Disease (CAD) by 2015 in India, and of these, 23 million would be younger than 40 years of age. ${ }^{1}$ The present study will enlighten the correlation of Atrioventricular conduction defects versus intraventricular conduction defects in acute myocardial infarction after thrombolytic era.
\end{abstract}

\begin{abstract}
AIMS AND OBJECTIVES
To study the prognosis of atrioventricular conduction blocks versus intraventricular conduction defects in patients with acute myocardial infarction.
\end{abstract}

\section{MATERIALS AND METHODS}

It is a prospective and comparative cohort study; 72 patients admitted in RLJH diagnosed as acute myocardial infarction who are with AV conduction blocks and myocardial infarction with intraventricular conduction blocks are included in the study. That is 36 patients with acute myocardial infarction with atrioventricular conduction blocks compared with 36 patients of myocardial infarction with intraventricular conduction blocks. Seven days followup is done to assess the prognosis of AV blocks versus intraventricular conduction blocks in acute myocardial infarction.

\section{RESULTS}

Both AV (75\%) and intraventricular (80\%) blocks (IV blocks) are more in males, but no significant difference between AV and IV blocks with respect to gender. Chest pain (86\%) is the common presentation for conduction disturbances in acute Myocardial Infarction (MI). Breathlessness is more specific for intraventricular blocks in acute MI. Anterior wall (52.8\%) is involved in intraventricular conduction blocks compared to AV Blocks (27.8\%). Inferior wall (55.6\%) is involved in AV blocks more than anterior Wall (41.7\%). In Killips staging most of AV blocks presented in stage 3 compared to IV block which have less risk (Stage 1) and better prognosis. Based on mortality AV blocks have more mortality of 33.3\% compared to Intraventricular blocks (8.3\%) in acute Myocardial Infarction (MI).

\section{CONCLUSION}

Hence taking all things together AV blocks are associated with greater risk or poor prognosis compared to intraventricular blocks in acute myocardial infarction according to this present study. A cross sectional study of the nutrient intake of rural Adolescent girls was carried out in four villages of the Department of Community Medicine, Katihar Medical College, Katihar.

\section{KEYWORDS}

A high Index of Suspicion is needed to make a Timely Diagnosis of type of Conduction Blocks in Acute Myocardial Infarction.

HOW TO CITE THIS ARTICLE: Reddy NS, Prasad BNR, Prabhakar K, et al. Study of prognosis of atrioventricular blocks versus intraventricular blocks in acute myocardial infarction. J Evolution Med Dent Sci 2016;5(4):246-252,

DOI: $10.14260 /$ jemds/2016/52

\section{INTRODUCTION}

Myocardial infarction is a Global epidemic, and is intimidating large as the new epidemic afflicting population worldwide. According to the National Commission on Macro-economics and Health, there would be around 62 million patients with Coronary Artery Disease (CAD) by 2015 in India and of these 23 million would be younger than 40 years of age. 1

Financial or Other, Competing Interest: None.

Submission 07-11-2015, Peer Review 10-11-2015,

Acceptance 08-01-2016, Published 12-01-2016.

Corresponding Author:

Dr. Nelaballi Srichandhan Reddy,

Room No. 202, PG Mens Block,

Sri Devaraj Urs Medical College,

Tamaka, Kolar-563101,

Karnataka, India.

E-mail: srichandhanreddy@gmail.com

DOI:10.14260/jemds/2016/52
Conduction defects are one of the most common complications which occur following Acute Myocardial Infarction (AMI), which results in increased mortality in these patients with Acute Myocardial infarction. ${ }^{2}$

The mortality rate associated with uncomplicated infarctions is less than $20 \%$, but the mortality rate when some form of bundle branch block is present may be as high as $60 \%$. Brady arrhythmias are defined as a heart rate below 60 beats per minute $(\mathrm{bpm})$. These can be further categorized on the basis of the level of disturbances in the hierarchy of the normal cardiac conduction system. ${ }^{3}$ In this article, we will review the pathophysiology, diagnosis, prognosis, and treatment options of AV blocks versus intraventricular conduction blocks these rhythm disorders. ${ }^{4}$ 
The present study will enlighten the correlation of AV conduction defects versus intraventricular conduction defects in acute myocardial infarction after thrombolytic era.

\section{OBJECTIVES}

To study the prognosis of $\mathrm{AV}$ conduction blocks versus Intraventricular conduction defects in patients with acute myocardial Infarction.

\section{MATERIALS AND METHODS}

\section{Source of Data}

It is a prospective and comparative cohort study; 72 Patients admitted in RLJH out of which 36 are AV conduction blocks and 36 are intraventricular conduction blocks with acute myocardial infarction; 7 days follow up is done to assess the prognosis of $\mathrm{AV}$ blocks versus intraventricular conduction blocks in acute myocardial infarction.

\section{Inclusion Criteria}

1. Patients satisfying WHO criteria of myocardial infarction, had 2 of the 3 of following. 4

a. Symptoms of ischemia.

b. Evolutionary ECG changes are seen

c. A rise of cardiac markers.

The diagnosis of arrhythmia was carried out as per AHA guidelines and treated accordingly.

2. Patients above the age of 18 years are included in the study.

3. Patients having myocardial infarction with atrioventricular blocks (AV blocks) and intraventricular conduction blocks (IV blocks).

\section{Exclusion Criteria}

1. Patients with pre-existing conduction blocks.

2. Patients with pre-existing heart disease (Congenital heart disease, cardiomyopathy, rheumatic heart diseases).

3. Patients taking drugs that cause conduction blocks like clonidine, methyldopa, verapamil and digoxin.

\section{Method of Collection of Data}

After taking history of patients and doing clinical examination investigations including ECG, serum cardiac markers and ECHO are done, acute myocardial infarction diagnosed based on above mentioned criteria. Follow up for a period of 7 days after acute myocardial infarction by series of ECG'S and assessment is based on following variables they are area of infarction, mortality, hypotension, Killips staging and ejection fraction.

\section{Statistical Methods}

Data was entered into Microsoft excel data sheet and was analysed using SPSS 22 version software. Independent ' $t$ ' test was used as test of significance to identify the mean difference between two groups. Mann Whitney U test was used for quantitative variables not following normal distribution.

\section{RESULTS}

Seventy two patients are taken in the study, out of which 36 patients had AV blocks and 36 patients were Intraventricular blocks. Mean age of subjects in the study was $57 \pm 13.12$ years. Majority of subjects were in the age group $>60$ years $(37.5 \%)$.
Majority of subjects were Males (77.8\%) and 22.2\% were females. In the study majority of subjects were from rural residence $(91.9 \%)$ and $8.3 \%$ were from urban area; $29.2 \%$ of subjects were smokers and $18.1 \%$ were alcoholics; $52.8 \%$ of subjects had history of HTN in the study.

An $83.3 \%$ of subjects presented with chest pain and $20.8 \%$ presented with breathlessness. Majority of subjects had anterior MI (47.2\%) followed by inferior MI (41.7\%), anterolateral MI (9.7\%) and posterolateral MI (1.4\%).

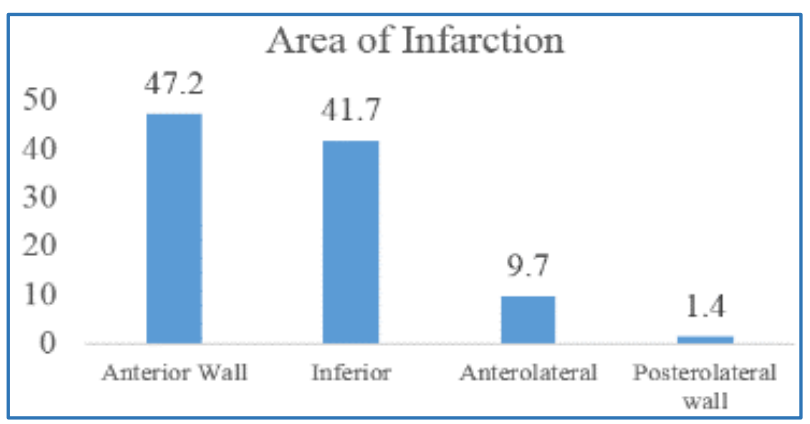

Fig. 1: Bar Diagram Showing Area of Infarction

\begin{tabular}{|l|c|c|c|}
\hline \multicolumn{2}{|c|}{} & Frequency & Percent \\
\hline \multirow{3}{*}{ Hypotension } & No & 56 & 77.8 \\
\cline { 2 - 4 } & Yes & 16 & 22.2 \\
\cline { 2 - 4 } & Total & 72 & 100.0 \\
\hline \multicolumn{3}{|c|}{ Table 1: Distribution of Subjects according to } \\
Hypotension
\end{tabular}

In the study $22.2 \%$ of subjects had hypotension on admission.

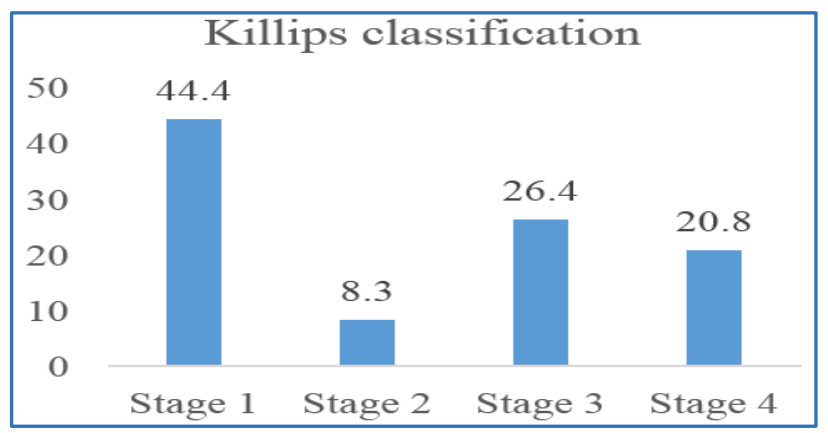

Fig. 2: Bar Diagram showing Killips Classification

According to Killips classification $44.4 \%$ were stage 1 , $8.3 \%$ were stage $2,26.4 \%$ were stage 3 and $20.8 \%$ were stage 4. On ECHO $31.9 \%$ had ejection fraction $<45 \%, 66.7 \%$ had 45 to $60 \% \mathrm{EF}$ and $1.4 \%$ had $\mathrm{EF}>60 \%$.

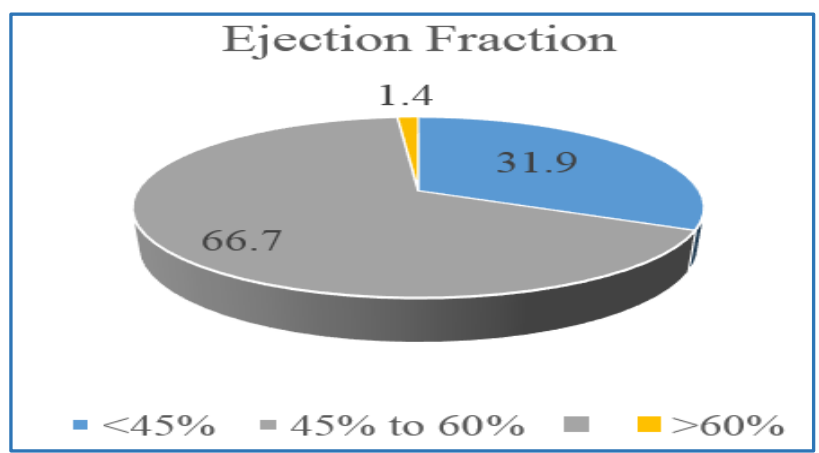

Fig. 3: Pie Diagram showing Ejection Fraction 


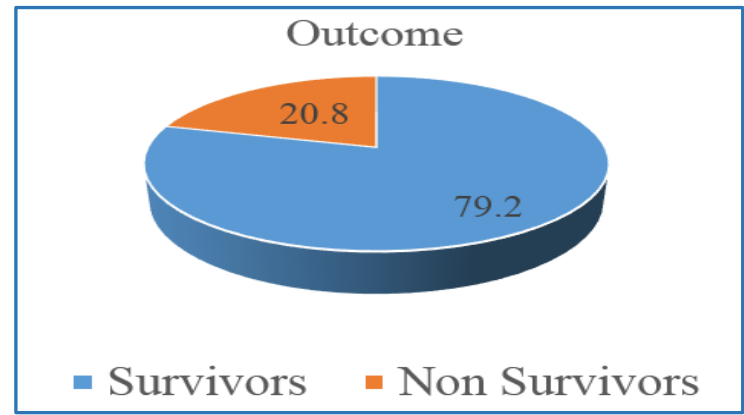

Fig. 4: Pie Diagram showing Outcome

In the study $79.2 \%$ had good outcome and $20.8 \%$ had mortality during the course of treatment.

\begin{tabular}{|c|c|c|c|}
\hline \multicolumn{2}{|c|}{} & Frequency & Percent \\
\hline \multirow{3}{*}{ TPI Insertion } & No & 61 & 84.7 \\
\cline { 2 - 4 } & Yes & 11 & 15.3 \\
\cline { 2 - 4 } & Total & 72 & 100.0 \\
\hline \multicolumn{3}{|c|}{ Table 2: Temporary Pacemaker } \\
In Situ Insertion in subjects \\
\hline
\end{tabular}

In $15.3 \%$ of subjects TPI was inserted. Hence confounding was removed by matching the subjects in both groups.

There was no significant association between Type of block and Age, Gender and Residence.

Majority of subjects in both block presented with Chest pain. There was no significant difference, whereas $30.6 \%$ of IV block presented with breathlessness and only $11.1 \%$ in AV block presented with breathlessness. This observation was statistically significant.

\begin{tabular}{|c|c|c|c|c|c|c|}
\hline & \multicolumn{4}{|c|}{$\begin{array}{c}\text { Type of } \\
\text { Block }\end{array}$} & \multirow{3}{*}{$\begin{array}{c}P \\
\text { value }\end{array}$} \\
\hline & & \multicolumn{2}{|c|}{$\begin{array}{l}\text { AV } \\
\text { block }\end{array}$} & \multicolumn{2}{|c|}{$\begin{array}{c}\text { Intraventricular } \\
\text { Block }\end{array}$} & \\
\hline & & Count & $\%$ & Count & $\%$ & \\
\hline \multirow{2}{*}{ Smoker } & No & 30 & $83.3 \%$ & 21 & $58.3 \%$ & \multirow{2}{*}{0.020} \\
\hline & Yes & 6 & $16.7 \%$ & 15 & $41.7 \%$ & \\
\hline \multirow{2}{*}{ Alcoholic } & No & 32 & $88.9 \%$ & 27 & $75.0 \%$ & \multirow{2}{*}{0.126} \\
\hline & Yes & 4 & $11.1 \%$ & 9 & $25.0 \%$ & \\
\hline & & $\begin{array}{l}\text { socio } \\
\text { erso }\end{array}$ & Histc & $\begin{array}{l}n T y \\
f s u\end{array}$ & fBlock & \\
\hline
\end{tabular}

A $41.7 \%$ of IV block subjects were smokers and $16.7 \%$ of AV block subjects were smokers. This observation was statistically significant. There was no significant association between type of block and alcohol intake. There was no significant association between type of block and HTN history.

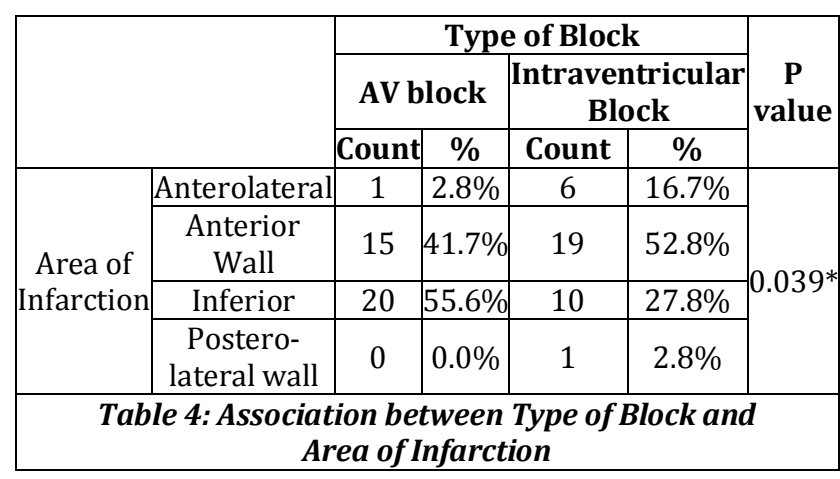

There was significant association between type of block and Area of Infarction, i.e. Majority of AV block subjects had Inferior wall MI (55.6\%) and Majority of IV block subjects had anterior wall (52.8\%) MI. There was no significant difference between type of block and hypotension.

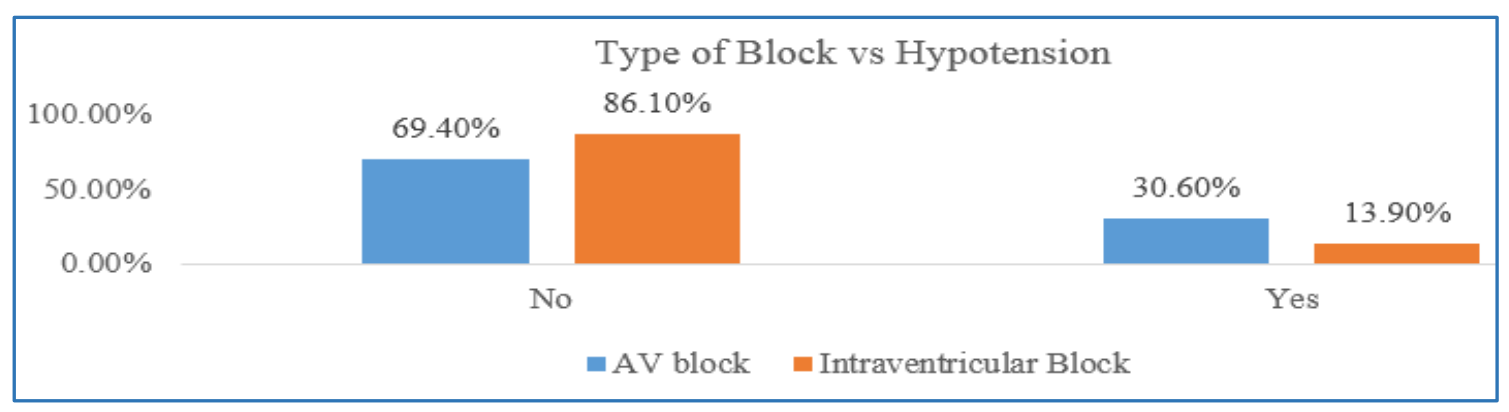

Fig. 5: Bar Diagram showing Association between Type of Block and Hypotension

In the study majority of subjects in AV block had stage 3 Killips classification (36.1\%) and in IV block majority of them had Stage 1 Killips classification (61.1\%). This observation was statistically significant.

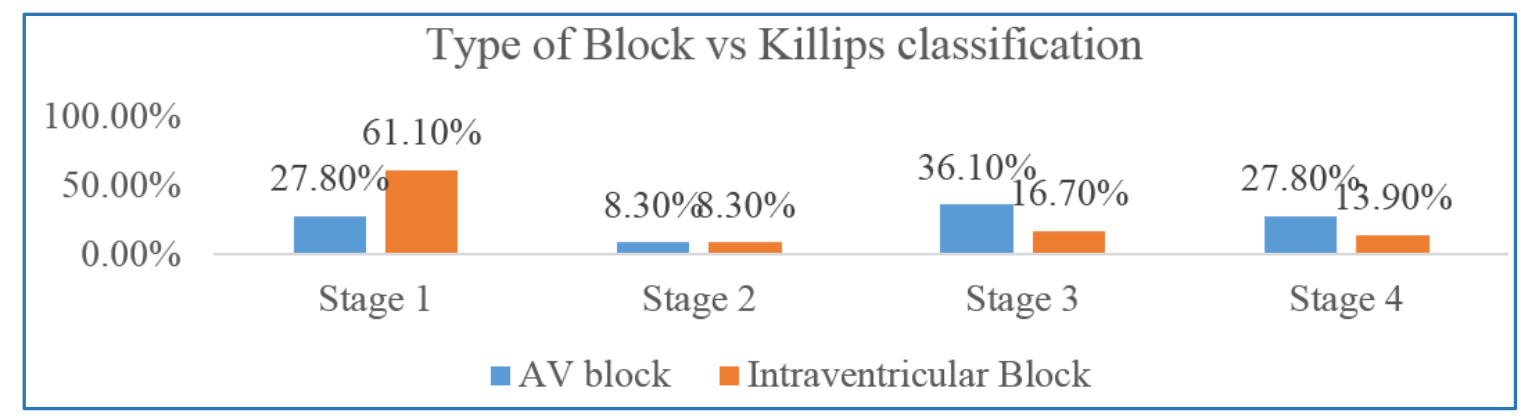

Fig. 6: Bar Diagram showing Association between Type of Block and Killips Classification 
In the study 33.3\% of subjects in AV block had mortality and in IV block $8.3 \%$ had mortality. This observation was statistically significant.

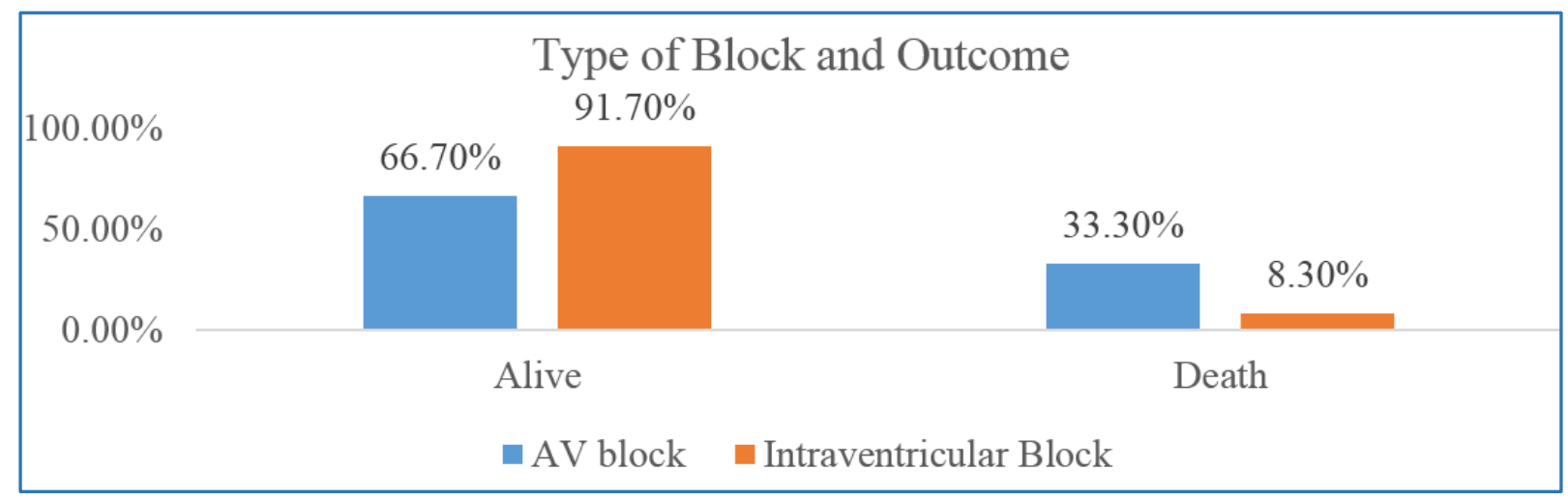

Fig. 7: Bar Diagram showing Association between Type of Block and Outcome

\begin{tabular}{|c|c|c|c|c|c|c|}
\hline & \multicolumn{4}{|c|}{ Type of Block } & \multirow{3}{*}{$\begin{array}{c}P \\
\text { value }\end{array}$} \\
\hline & & \multicolumn{2}{|c|}{ AV block } & \multicolumn{2}{|c|}{$\begin{array}{c}\text { Intraventricular } \\
\text { Block }\end{array}$} & \\
\hline & & Count & $\%$ & Count & $\%$ & \\
\hline \multirow{2}{*}{$\begin{array}{c}\text { TPI } \\
\text { Insertion }\end{array}$} & No & 27 & $75.0 \%$ & 34 & $94.4 \%$ & \multirow{2}{*}{$0.022^{*}$} \\
\hline & Yes & 9 & $25.0 \%$ & 2 & $5.6 \%$ & \\
\hline \multicolumn{7}{|c|}{$\begin{array}{l}\text { Table 5: Association between } \\
\text { ype of Block and TPI Classification }\end{array}$} \\
\hline
\end{tabular}

In the study $25 \%$ of subjects in AV block were inserted with TPI and in IV block 5.6\% had TPI insertion. This observation was statistically significant.

There was no significant association between Duration of hospital stay and Type of block.

\section{DISCUSSION}

At least $75 \%$ of patients with AMI have arrhythmia in the periinfarct period, and also that majority of deaths occur secondary to development of arrhythmias. ${ }^{5}$ The etiology of AVB in the setting of STEMI is thought to be multifactorial and dependent on the location of the culprit lesion. ${ }^{6-7}$ The AV nodal artery normally arises from the right coronary artery. ${ }^{8}$ and the ischemic insult caused by STEMI is thought to be sufficient to cause a transient dysfunction of the conduction fibers.

In addition, AVB is thought to be provoked by enhanced parasympathetic tone or local release of potassium or adenosine. ${ }^{9}$ In the thrombolytic era, it was shown that thrombolytic therapy may paradoxically precipitate the development of AVB. ${ }^{10}$ It was suggested that the reperfusion of the obstructed coronary artery induces a surge of afferent vagal activity that in turn induced a Atrioventricular Block.

High degree AVB has consistently been found to mark an adverse short-term mortality, whereas the long-term impact remained questionable. ${ }^{11,12}$ Gang et al. ${ }^{13}$

In the present study we assess the prognosis of atrioventricular blocks versus intraventricular blocks in acute MI. This is based on 6 variables and comparing them for a duration of 7 days. Conduction blocks chiefly seen in age group $>60$ years $(37.1 \%)$. Conduction disturbances in MI our study show male $(77 \%)$ predominance. Among all the patients included in the study majority of them presented with chief complaint of chest pain (83.3\%), followed by breathlessness (20.8\%). Smoking history is present in $29.2 \%$ of patients.
Anterior wall is most commonly involved in myocardial infarction with conduction disturbances.

Hypotension is present in 16 patients $(22.2 \%)$, whereas the rest are normotensive. Majority of them presented in Killips stage 1 (44.4\%) followed by Killips stage $3(26.4 \%)$ to the hospital. Ejection fraction in majority of patients $(66.7 \%)$ included in the study is between $45-60 \%$. About $20 \%$ of patients died in spite of the above treatment.

\section{ASSESS ATRIOVENTRICULAR BLOCK (AV BLOCK) VERSUS INTRAVENTICULAR}

Block (Intraventricular Block) in Different Age Groups

AV blocks are more (36\%) in age group more than 60 years compared to other age groups. In intraventricular blocks are more $(38 \%)$ in age group more than 60 years compared to other age groups. But as the "p" value is insignificant we cannot establish a correlation between age group and different types of block. Ahmadalli Shirafkhan.14 MITA Mehrad study of conduction disturbances in acute myocardial infarction: a clinical study and brief review of literature. ${ }^{15}$ the incidence AV blocks and intraventricular blocks in elderly is 33\% and 64\% respectively.

\begin{tabular}{|c|c|c|}
\hline & $\begin{array}{c}\text { AHMADALLI } \\
\text { SHIRAFKHAN, } \\
\text { MITA MEHRAD } \\
\text { STUDY }\end{array}$ & $\begin{array}{c}\text { PRESENT } \\
\text { STUDY }\end{array}$ \\
\hline AV BLOCK & $33 \%$ & $36 \%$ \\
\hline $\begin{array}{c}\text { INTRAVENTRICULAR } \\
\text { BLOCK }\end{array}$ & $64 \%$ & $38 \%$ \\
\hline \multicolumn{2}{|c|}{ Table 6: Comparing Present Study to Ahmadalli } \\
Shirafkhan, Mita Mehrad Study \\
\hline
\end{tabular}

\section{Compare AV Block Versus Intraventriclar Block in different Gender}

About 27 (75\%) members of the $36 \mathrm{AV}$ blocks are present in males. About $29(80.1 \%)$ members of the 36 Intraventricular blocks seen in males. But as the "p" value is insignificant we cannot establish a significant correlation between gender and the type of block. In a previous study atrioventricular blocks and bundle branch blocks in acute myocardial infarction males have an incidence of $62.5 \%$ and $65.5 \%$ respectively. Females have incidence of $65.71 \%$ and $34.29 \%$ respectively. 


\begin{tabular}{|c|c|c|}
\hline & $\begin{array}{c}\text { Macarie C, Năstase- } \\
\text { Melicovici D Study }\end{array}$ & $\begin{array}{c}\text { Present } \\
\text { Study }\end{array}$ \\
\hline $\begin{array}{c}\text { TYPE OF } \\
\text { BLOCK }\end{array}$ & IV BLOCK & IV BLOCK \\
\hline Male & $62.57 \%$ & $80.1 \%$ \\
\hline Female & $37.43 \%$ & $19.9 \%$ \\
\hline \multicolumn{2}{|c|}{ Table 7: Comparing Present Study to Macarie C, } \\
Năstase-Melicovici D Study \\
\hline
\end{tabular}

\begin{tabular}{|c|c|c|}
\hline & $\begin{array}{c}\text { Macarie C, Năstase- } \\
\text { Melicovici D Study }\end{array}$ & $\begin{array}{c}\text { Present } \\
\text { Study }\end{array}$ \\
\hline $\begin{array}{c}\text { TYPE OF } \\
\text { BLOCK }\end{array}$ & AV BLOCK & AV BLOCK \\
\hline Male & $65.71 \%$ & $75 \%$ \\
\hline Female & $34.29 \%$ & $25 \%$ \\
\hline \multicolumn{2}{|c|}{ Table 8: Comparing Present Study to Macarie C, } \\
Năstase-Melicovici D Study \\
\hline
\end{tabular}

Compare AV Block Versus Intraventriclar Block in different Residences

About $95 \%$ of the AV blocks seen in rural population. About $88.7 \%$ of Intraventricular (IV) blocks seen in rural population. But as the " $P$ " value is insignificant we cannot establish the correlation between residence and the type of block.

Compare AV Block Versus Intraventriclar Block in different Presentations

Majority of them presented with chest pain as the main symptom, second most common complaint is breathlessness. Breathlessness is specific symptom for those who have MI with intraventricular block than AV block. As the $p$ value is significant, correlation can be made between breathlessness in MI with IV block than AV block. As $30.6 \%$ of IV block presented with breathlessness and only $11.1 \%$ in AV block presented with breathlessness. This observation was statistically significant.

Compare AV Block Versus Intraventriclar Block in Personal Habits

Two things considered are the smoking and alcohol intake among those smoking is more commonly associated with IV blocks; $41.7 \%$ of IV block subjects were smokers and $16.7 \%$ of AV block subjects were smokers. This observation was statistically significant. There was no significant association between type of block and alcohol intake. In another study $30 \%$ increase in risk of IV blocks noticed in them patients. In other study done by Macarie C, Năstase-Melicovici D study atrioventricular blocks and bundle branch blocks in acute myocardial infarction. ${ }^{15}$ Smoking patients $24 \%$ risk of IV blocks compared to AV blocks that is $20 \%$.

\begin{tabular}{|c|c|c|}
\hline & $\begin{array}{c}\text { Macarie C, } \\
\text { Năstase- } \\
\text { Melicovici D } \\
\text { Study }\end{array}$ & $\begin{array}{c}\text { Present } \\
\text { Study }\end{array}$ \\
\hline & Smoking & Smoking \\
\hline AV BLOCK & $20 \%$ & $16.7 \%$ \\
\hline $\begin{array}{c}\text { INTRAVENTRICULAR } \\
\text { BLOCK }\end{array}$ & $24.4 \%$ & $41.7 \%$ \\
\hline \multicolumn{2}{|c|}{ Table 9: Comparing Present Study to Macarie C, } \\
Năstase-Melicovici D Study \\
\hline
\end{tabular}

Compare AV Block Versus Intraventriclar Block in Normotensive and Hypertensive Patients

Percentage of people with AV block (58\%) versus Intraventricular block (47\%). But the " $\mathrm{P}$ " value is insignificant. Hence, there was no significant association between type of block and HTN history. In other study done by Macarie C, Năstase-Melicovici D study atrioventricular blocks and bundle branch blocks in acute myocardial infarction. Atrioventricular blocks and bundle branch blocks in acute myocardial Infarction. Hypertension patients $\mathrm{AV}$ blocks incidence is $56.6 \%$ and for IV blocks is $60.6 \%$.

\begin{tabular}{|c|c|c|}
\hline & $\begin{array}{c}\text { Hypertension } \\
\text { Macarie C, } \\
\text { Năstase- } \\
\text { Melicovici D } \\
\text { study }\end{array}$ & $\begin{array}{c}\text { Hypertension } \\
\text { (Present } \\
\text { Study) }\end{array}$ \\
\hline AV BLOCK & $56.2 \%$ & $\mathbf{5 8 \%}$ \\
\hline $\begin{array}{c}\text { INTRAVENTRICULAR } \\
\text { BLOCK }\end{array}$ & $60.6 \%$ & $\mathbf{4 7 \%}$ \\
\hline
\end{tabular}

Table 10: Comparing Present Study to Macarie C, Năstase-Melicovici D study

\section{Compare AV Block Versus Intraventriclar Block in View} of Area of Infarction

There was significant association between type of block and Area of Infarction. I.e. Majority of AV block subjects had Inferior wall MI (55.6\%) and Majority of IV block subjects had anterior wall (52.8\%) MI. Whereas in Macarie C, NăstaseMelicovici D, Study, Majority of Intra Ventricular block subjects had Inferior wall MI (55.6\%) and Majority of IV block subjects had anterior wall (52.8\%) MI.

\begin{tabular}{|c|c|c|}
\hline IV BLOCK & $\begin{array}{c}\text { Macarie C, Năstase- } \\
\text { Melicovici D Study }\end{array}$ & $\begin{array}{c}\text { Present } \\
\text { Study }\end{array}$ \\
\hline $\begin{array}{c}\text { INFERIOR } \\
\text { WALL }\end{array}$ & $42 \%$ & $\mathbf{5 2 \%}$ \\
\hline $\begin{array}{c}\text { ANTERIOR } \\
\text { WALL }\end{array}$ & $49 \%$ & $\mathbf{2 7 \%}$ \\
\hline \multicolumn{2}{|c|}{ Table 11: Comparing Present Study to Macarie C, } \\
Năstase-Melicovici D Study \\
\hline
\end{tabular}

Compare AV Block Versus Intraventricular Block in Hypotensive and Normotensive Patients

The percentage of people with hypotension with conduction block in the present study. There was no significant difference between type of block and hypotension in this study. In a study by Elena B. Sgarbossa, MD, Sergio L. Pinski, "Acute Myocardial Infarction and Complete Bundle Branch Block A Hospital Admission Clinical Characteristics and Outcome in the Thrombolytic Era."16 The incidence of hypotension in AV blocks is $38.8 \%$, whereas hypotension in AV block seen in $38.8 \%$ cases and intraventricular block is $92 \%$.

\section{Compare AV Block Versus Intraventricular Block Based on} Killip Classification

In the study majority of subjects in AV block had stage 3 Killips classification (36.1\%) and in IV block majority of them had Stage 1 Killips classification (61.1\%). This observation was statistically significant. Hence, AV block is associated with more risk as most of them presented with Killips stage 3. Elena B. Sgarbossa, MD, Sergio L. Pinski, "Acute Myocardial Infarction and Complete Bundle Branch Block A Hospital Admission: Clinical Characteristics and Outcome in the 
Thrombolytic Era."16 AV Blocks and intraventricular blocks in stage 4 are $38.8 \%$ and $92 \%$ respectively. Intraventricular block has poor prognosis in previous study.

\begin{tabular}{|c|c|c|}
\hline & $\begin{array}{c}\text { HYPOTENSION } \\
\text { ELENA B. } \\
\text { GARBOSSA, MD } \\
\text { STUDY }\end{array}$ & $\begin{array}{c}\text { PRESENT } \\
\text { STUDY }\end{array}$ \\
\hline & KILLIP STAGING & $\begin{array}{c}\text { KILLIP } \\
\text { STAGING }\end{array}$ \\
\hline AV BLOCK & Stage4 38.8\% & $\begin{array}{c}\text { Stage 3 } \\
(36.1 \%)\end{array}$ \\
\hline $\begin{array}{c}\text { INTRAVENTICULAR } \\
\text { BLOCK }\end{array}$ & Stage 4 92\% & $\begin{array}{c}\text { Stage } 1 \\
(61.1 \%)\end{array}$ \\
\hline Table 12: Comparing Present Study to Hypotension \\
Elena B. Sgarbossa, MD, Study \\
\hline \multicolumn{3}{|c}{}
\end{tabular}

Hence, a significant risk is associated with AV block in acute MI than intraventricular block in this present study.

\section{Compare AV Block Versus Intraventriclar Block Based on Ejecton Fraction}

$\mathrm{AV}$ blocks with $\mathrm{EF}<45 \%$ is $27 \%$ and Intraventricular blocks with $\mathrm{EF}<45 \%$ is $36 \%$, but there is no significant relation. So the ejection fraction in patients with intraventricular conduction defects is associated with $\mathrm{EF}<45 \%$. A previous study was done by Ahmadalli Shirafkhan, Mitramehad Study shows no significant relation between type on conduction blocks and ejection fraction this support our study.

\section{Compare AV Block Versus Intraventriclar Block in View of Mortality}

In the study $33.3 \%$ of subjects in AV block had mortality and in IV block $8.3 \%$ had mortality. This observation was statistically significant. Hence, AV blocks are associated with high mortality compared to intraventricular blocks in view of mortality. In a previous study by M. Scheinman, M.D. and B. Brenman, B.A. Clinical and Anatomic Implications of Intraventricular Conduction Block in Acute Myocardial Infarction study mortality of AV block. ${ }^{17}$ and IV block are $38 \%$ and IV block is $18 \%$. This supports our study further.

\begin{tabular}{|c|c|c|}
\hline & $\begin{array}{c}\text { By M. } \\
\text { SCHEINMAN, } \\
\text { M.D., AND B. } \\
\text { BRENMAN, B.A. } \\
\text { Study }\end{array}$ & $\begin{array}{c}\text { Present } \\
\text { Study }\end{array}$ \\
\hline AV block mortality & $38 \%$ & $33 \%$ \\
\hline $\begin{array}{c}\text { Intraventricular } \\
\text { blocks }\end{array}$ & $18 . \%$ & $8.3 \%$ \\
\hline $\begin{array}{c}\text { Table 13: Comparing Present Study to Hypotension by } \\
\text { M. Scheinman, M.D., and B. Brenman, B. A. Study }\end{array}$ \\
\hline
\end{tabular}

Hence, based on the variables chosen Killips staging AV block presented in stage 3 and mortality is also significant in the AV block compared to Intra-ventricular block. Involving anterior wall is more risk of mortality than other walls of the heart, intraventricular blocks commonly involves anterior wall, AV bocks most commonly involves inferior wall followed by anterior wall. Hence, taking all things together AV blocks are associated with greater risk or poor prognosis compared to intraventricular blocks.

\section{CONCLUSION}

Hence, taking all variables together AV blocks are associated with greater risk or poor prognosis compared to intraventricular blocks in acute myocardial infarction according to this present study.

\section{REFERENCES}

1. Rissam HS, Kishore S, Trehan N. Coronary artery disease in young Indians-The missing link. Journal, Indian academy of clinical medicine. 2001;2(3):128-32.

2. Ahmadali Shirafkan1, Mitra Mehrad2, Ali Gholamrezanezhad3,4, et al. Conduction disturbance in acute myocardial infarction. Hellenic J Cardial 2009;50:179-184.

3. Rubart M, Zipes DP. Arrhythmias, sudden death and syncope. En: Libby P, Bonow RO, Mann DL, Zipes D, editors. Braunwald's Heart Disease. Philadelphia: Saunders Elsevier, 2008; 909.

4. Podeo Tunstall H, Kuulasmaa K, Amoyenel $\mathrm{P}$, et al. Myocardial infarction and coronary deaths in World Health Organisation MONICA project. Circulation 1994;90:583-612.

5. Ghuran AV, Camm AJ. Ischemic heart disease presenting as arrhythmias. BMB. 2001;59:193-210.

6. Waller BF, Gering LE, Branyas NA, et al. Anatomy, histology and pathology of the cardiac conduction system. Part V Clin Cardiol 1993;16(7):565-9.

7. Webb SW, Adgey AA, Pantridge JF. Autonomic disturbance at onset of acute myocardial infarction. $\mathrm{Br}$ Med J 1972;3(5818):89-92.

8. Wesley RC Jr, Lerman BB, DiMarco JP, et al. Mechanism of atropine-resistant atrioventricular block during inferior myocardial infarction: possible role of adenosine. J Am Coll Cardiol 1986;8(5):1232-4.

9. Van der Hauwaert LG, Stroobandt R, Verhaeghe L. Arterial blood supply of the atrioventricular node and main bundle. Br Heart J 1972;34(10):1045-51.

10. Simons GR, Sgarbossa E, Wagner G, Califf RM, Topol EJ, Natale A. Atrioventricular and intraventricular conduction disorders in acute myocardial infarction: a reappraisal in the thrombolytic era. Pacing Clin Electrophysiol 1998;21(12):2651-63.

11. Behar S, Zissman E, Zion $\mathrm{M}$, et al. Complete atrioventricular block complicating inferior acute wall myocardial infarction: short- and long-term prognosis. Am Heart J 1993;125(6):1622-7.

12. Meine TJ, Al-Khatib SM, Alexander JH, et al. Incidence, predictors and outcomes of high-degree atrioventricular block complicating acute myocardial infarction treated with thrombolytic therapy. Am Heart J 2005;149(4):670-4.

13. Gang UJ, Hvelplund A, Pedersen S, et al. High-degree atrioventricular block complicating ST-segment elevation myocardial infarction in the era of primary percutaneous coronary intervention. Europace 2012;14(11):1639-45.

14. Ahmadalli Shirafkhan, Mita Mehrad. Study of conduction disturbances in acute myocardial infarction: a clinical study and brief review of literature. Hellenic J Cardiol 2009;50:179-184. 
15. Macarie $\mathrm{C}$, et al. Atrioventricular blocks and bundle branch blocks in acute myocardial infarction. Acta Medica Marisiensis. Jan 2012, Vol. 58 Issue 1, p35-38. 4p. 3 Charts, 7 Graphs.

16. Elena B Sgarbossa, Sergio L Pinski, Shaun G, et al. Acute myocardial infarction and complete bundle branch block at hospital admission: clinical characteristics and outcome in the thrombolytic era. Journal of The American College of Cardiology Volume 31, Issue 1, January 1998, Pages 105-110 doi:10.1016/S07351097(97)00446-4.
17. By Scheinman $M$ and B Brenman, BA. Clinical and anatomic implications of intraventricular conduction block in acute myocardial infarction circulation. 1972;46:753-760doi: 10.1161/01.CIR.46.4.753. 